\title{
Teachers’ recruitment process via MCDM methods: A case study in Bangladesh
}

\author{
C. L. Karmaker ${ }^{\mathrm{a}^{*}}$ and M. Saha ${ }^{\mathrm{b}}$
}

${ }^{a}$ Department of Industrial and Production Engineering, Jessore University of Science and Technology, Jessore, Bangladesh ${ }^{b}$ Department of Civil Engineering, Bangladesh University of Engineering and Technology, Dhaka, Bangladesh

\begin{tabular}{|c|c|}
\hline C H R O N I C L E & A B S T R A C T \\
\hline $\begin{array}{l}\text { Article history: } \\
\text { Received March 25, } 2015 \\
\text { Received in revised format June } \\
12015 \\
\text { Accepted June } 102015 \\
\text { Available online } \\
\text { June } 102015 \\
\text { Keywords: } \\
\text { Recruitment Process } \\
\text { Teaching Staff Selection } \\
\text { Multi criteria decision making } \\
\text { AHP-TOPSIS } \\
\text { FAHP-TOPSIS }\end{array}$ & $\begin{array}{l}\text { Evaluation of faculty members is very significant for educational organization to prompt } \\
\text { reputation of the organization and to provide quality education. Teaching staff, the pillars of } \\
\text { the educational institution, can change the whole nation stimulating the magnet of interest, } \\
\text { knowledge, and wisdom in the pupils. Selecting a better academic staff among the others is } \\
\text { very crucial for Human Resources Management (HRM) as the success of any organization } \\
\text { solely depends on how well it selects its manpower. Institute managing committee must have } \\
\text { a reliable technique to judge a teachers' ranking through multiple conflicting criteria because } \\
\text { different teachers have various capabilities. In Bangladesh, it is a common practice in public } \\
\text { engineering universities to select teachers only having good academic records. But teaching } \\
\text { staff selection problem is a multi-staged decision-making problem having both quantitative } \\
\text { and qualitative criteria. It is evident that it has become challenging as the number of alternatives } \\
\text { and conflicting criteria increases. In this paper, a structured framework has been developed } \\
\text { using MCDM methods both in fuzzy as well as non-fuzzy environments in the renowned } \\
\text { engineering university of Bangladesh, where seven candidates under fifteen different sub- } \\
\text { criteria are evaluated and ranked. The study helps the recruitment panel of educational } \\
\text { organization in Bangladesh select the most eligible academic staff for required posts. }\end{array}$ \\
\hline
\end{tabular}

\section{Introduction}

Education, the backbone of the nation, is necessary for socio-economic development and improvement of a country. It is considered as the primary ingredient of human resource development. Education, one of the MDGs in Bangladesh, has been viewed as a key to a better future and a vital tool to develop a nation. Over the past 2 decades, a trend of significant progress has been observed in educational sector of Bangladesh. The government, local community and non-governmental organizations are striving to reduce the illiteracy rate. The number of graduates is being accelerated every year but there is always a question about quality of these graduates as well as the educational institution with respect to quality teachers. Quality of higher education cannot be achieved without continuous assessment and enhancement of teacher's performance. The need for recruiting appropriate academic staff seems to be inevitable as the number of universities in Bangladesh is increasing as well as the government has tried to fulfill the promised goal.

\footnotetext{
* Corresponding author.

E-mail address: k.chitroleka@gmail.com (C. L. Karmaker) 
A real teacher is blessing to students who informs them about proper knowledge beyond classroom study as well as inspires them for bigger successes. He can show the right path to lead students to success by providing proper education. A teacher being a compass stimulates the magnet of valuable factors like interest, knowledge, wisdom etc. in the pupils. True teachers are role models having qualities that the students would like to have and affect us in a way that creates an urge within us to be a better human. According to Nikos Kazantzakis, "Ideal teachers are those who use themselves as bridges over which they invite their students to cross, then having facilitated their crossing, joyfully collapse, encouraging them to create bridges of their own." In Bangladesh, number of skilled teachers in educational environment is very few and majority of them are managing with quality.

The root problem is the recruitment \& selection process of academic staff. In Bangladesh, it is a common practice in educational organization to select teachers only having good academic records. But a teacher having good academic records may not necessarily be a good teacher (Hota et al., 2013). The selection of teaching personnel is defined as the process of selecting one that possess substantial qualities like up-to-date knowledge, communication skills, self-esteem and required qualifications to do his defined job in a proper way (Barber, 1998). In Bangladesh, the selection process of teaching staff is based on written and oral exams where there is no involvement of students. Recently, demo presentation beyond written test and oral exams is used in private universities. But student's opinion in selection is really absent in all these methods. Student's opinion must need to consider in ranking with other alternatives to achieve the accuracy and consistency in the evaluation process. So, the management must have a reliable technique to enrich the recruitment procedure and deal with multiple conflicting criteria as different teachers may have different quality of all these. In the wake of a rise in the role of recruitment process, the necessity for conducting substantial research has become unavoidable (Barber, 1998).

The aim of this study is to propose a model to find out the right personnel by using comparison of seven applicants. In the assessment procedure, analytical hierarchy process (AHP) as well as fuzzy AHP (FAHP) method has been applied to determine the weights of the criteria and to rank the candidates, TOPSIS (Technique for Order Preference by Similarity to Ideal Solution) method has been used. At last, a comparative analysis has been demonstrated. The summary view of this research has been shown in Fig. 1.

\section{Identification of evaluation criteria}

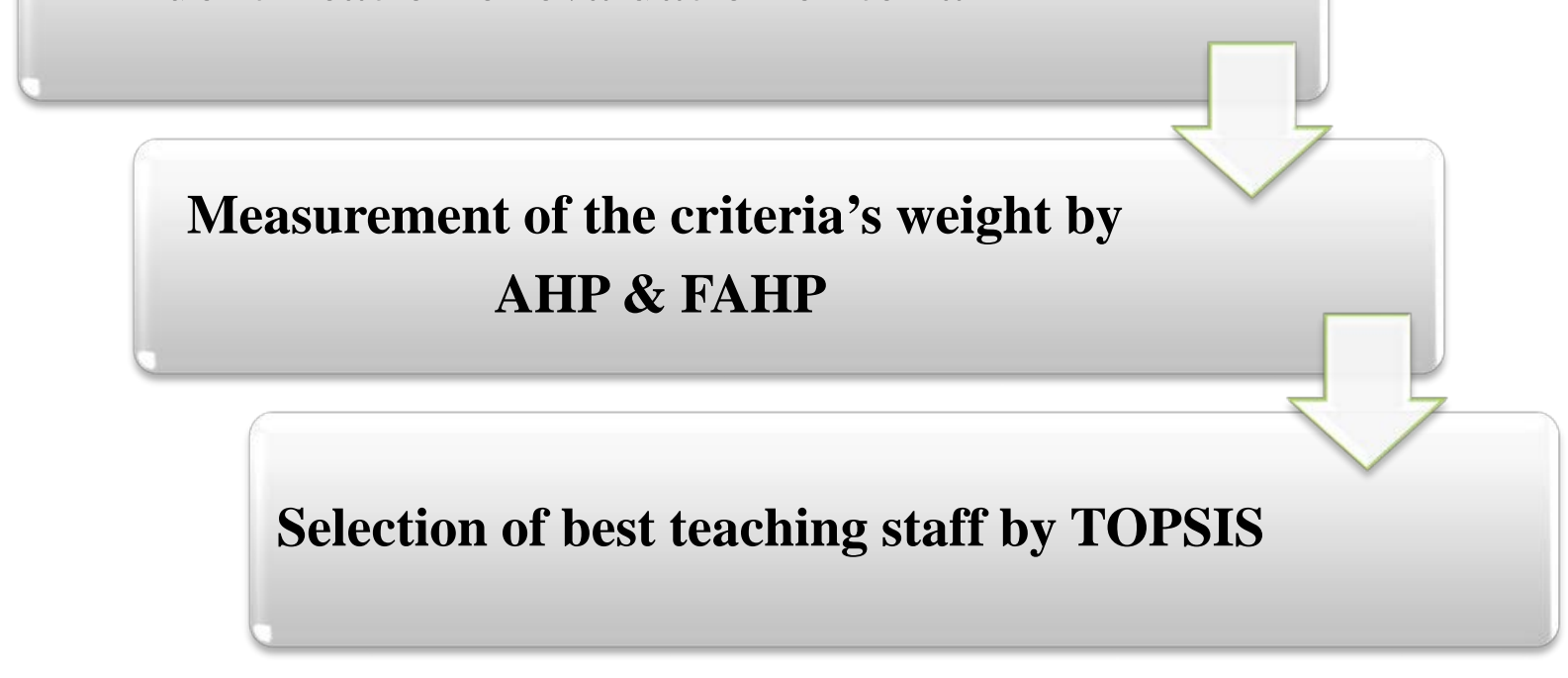

Fig.1. Steps of evaluation procedure 
The rest of this study is arranged as follows: The second section presents the detailed literature review. Section 3 frameworks the developed methodology and provides a stepwise depiction of the anticipated MCDM approaches. In Section 4, the application of the proposed framework for the right selection of teaching staff in the real world has been clarified. And finally, in section five, results of the application are presented and suggestions for the future studies are explained. This section wraps up this study.

\section{Literature review}

Selection of right teaching personnel in educational organization is very essential as the reputation of that organization solely depends on how well it selects its manpower. Besides, proper recruitment is very essential for the economic development of any country (Becker). It also introduces a foundation for upgrades and increments in the development of an organization. Teaching personnel selection issue is not at all a straight problem as different teachers may have various capabilities. To develop performance in terms of quality education \& responsiveness, institutions must determine their proper decisions. Modern universities are now facing the problems of selecting right personnel. The difficulty of the selection problem has driven the researchers to develop models that will prevent the bias and diminish the unfairness in the decision process. Teaching personnel selection problem can be considered as a multi-staged decision-making problem having both qualitative and qualitative conflicting criteria.

Various methods for personnel selection problem have been developed. Afshari et al. (2010) used simple additive weighting (SAW) approach in personnel selection problem. Jessop (2004) anticipated the minimally biased weight method with a view to helping decision makers in staff selection issue. Kousalya et al. (2006) used AHP to rank alternatives like counseling, infrastructure, making lecture more attractive etc. controlling student absenteeism in educational institutions. The weights of absenteeism criteria were calculated by AHP method. Finally, alternatives were ranked based on the preferential (priority) weights of criteria. Mahapatra and Khan (2007) developed a Neural Network (NN) approach for assessing service quality in technical education. Kelemenis and Askounis (2010) proposed a new TOPSIS-based multi criteria approach to help decision makers selecting right personnel. Radhika et al. (2013) developed a model using VIKOR method to assist decision makers to select academic staff. Ghosh (2011) presented a structured approach that combined AHP and TOPSIS methods for the performance evaluation of faculty members in engineering education. Here, AHP method is used to calculate the weights of the criteria and four alternatives in each attribute using ten students opinion of a specific department. Then TOPSIS is anticipated to rank the alternatives considering weights obtained from AHP method.

Besides, the assessable aspects of the personnel selection decision, qualitative not quantitative criteria having subjective factors that are difficult to enumerate, are needed to be measured. In addition to the conventional approaches, the multiple criteria decision-making methods such as AHP or ANP tend to be less effective in dealing with the imprecise or vague nature of the linguistic assessment for personnel selection problems. In real world applications, assessment of eligible alternatives for subjective criteria is expressed in linguistic terms (Karmaker \& Saha, 2015). For this, several researchers have incorporated fuzzy set theory to efficiently resolve the ambiguity obtained from the available information (Liang, 1999). Fuzzy set theory seems as an operative tool in dealing with the imprecise or uncertainty intrinsic in personnel selection process (Miller \& Feinzing, 1993; Karsak, 2001; Capaldo \& Zollo, 1992; etc.). In the literature, there are a number of studies that apply different fuzzy based decision making techniques to personnel selection problems.

Liang and Wang (1994) used fuzzy MCDM algorithm for finding out the most eligible personnel. Gungor et al. (2009) also proposed a model that applied fuzzy AHP method in a MCDM environment for staff selection problem. Here, the criteria hierarchy was prepared using a questionnaire and fuzzy linguistics variables were used to capture expert's opinion. Also, Chen (2009) presented a structured 
framework involving fuzzy logic and AHP methods to identify the appropriate personality qualities as well as main professional abilities. The model was developed with a view for enhancing the recruitment procedures as well as helping to choose the best employee. Gangadhar et al. (2013) developed a structure that includes fuzzy logic based MCDM method named FAHP to find out teachers ranking. This model will help an institute management take proper decision about teacher's performance evaluation as well as assigning new responsibilities considering their quality. In addition, Mikhailov (2002) applied the fuzzy analytical approach to partnership selection problem.

Rouyendegh and Erkan (2012) applied an MCDM method named Fuzzy ELECTRE method in order to find out the most suitable academic staff. He also used analytic hierarchy process under fuzzy environment (FAHP) for academic staff selection. Neogi et al. (2011) implemented a cascaded fuzzy inference system for performance appraisal of university non-teaching staff. Few researchers have employed the comparative analysis of Multiple-criteria decision making (MCDM) techniques in personnel selection problem. Sameer et al. (2013) proposed a comparative analysis of different MCDM methods named SAW, WPM, AHP TOPSIS methods for evaluating academic staff in academic institutions. In this research, AHP \& fuzzy AHP both methods have been utilized to estimate the weights of teachers' performance evaluation criteria. Then, the final ranking of the eligible candidates is attained by using AHP-TOPSIS \& FAHP-TOPSIS methods, comparatively. A comparative analysis of ranking alternatives is performed under fuzzy \& non-fuzzy environments. This research can be considered to the literature, because it is first in educational arena to develop a structured framework that integrates AHP \& FAHP for determining weights and TOPSIS to rank alternatives.

\section{Research methodology}

Selection of right teaching staff in academic institutions is not an easy task and may vary even within the organizations. Many techniques have been used in the field of recruitment process. This process is not enough to take the right decisions as the selection of criteria/weights for the assessment and evaluation have to be more clearly specified. The process involves multiple uncertain and qualitative criteria that are difficult to measure. So Multiple-criteria decision analysis (MCDA) or Multiple-criteria decision making (MCDM) seems to be the best way for service quality performance analysis of the alternatives. Multiple-criteria decision analysis (MCDA) or MCDM is a sub-discipline and full-grown branch of operations research that is concerned with designing mathematical and computational tools to support the subjective evaluation of a finite number of decision alternatives under a finite number of performance criteria by a single decision maker or by a group (Lootsma, 1999). Determining the attributes is very crucial to MCDM as they play a very substantial role in the decision making process. Several methods have been proposed for solving related problems, but a major problem of MADM is that different techniques may yield different results for the same problem. Therefore, how to make trade-off between these conflicting attributes and then make a decision could pose a difficult problem (Cheng et al., 2012).

In this research, a combination of AHP-TOPSIS and FAHP-TOPSIS methods has been used in personnel selection problem. The weights of personnel selection criteria are determined using nonfuzzy AHP \& fuzzy AHP methods while TOPSIS approach is proposed for evaluating and ranking candidates.

\subsection{Determining the criteria weights under AHP approach}

The analytic hierarchy process (AHP) is a multiple criteria decision making tool for organizing and analyzing complex decisions and firstly developed by Saaty (1980). This method is used to solve complex decision making problem having several attributes by modeling unstructured problem under study into hierarchical forms of elements. The essential components of hierarchical system are the main goal, criteria that affect the overall goal, sub-criteria that influence the main-criteria and finally the 
alternatives available to the problem. To obtain the degree of relative importance of elements at each level, a pair-wise comparison matrix is developed using Saaty 1-9 preference scale as shown in Table 1 . Then the eigenvector and the maximum eigenvalue $\left(\lambda_{\max }\right)$ are derived from pair-wise comparison matrix. The significance of the eigenvalue is to assess the strength of the consistency ratio CR (Saaty, 1980) of the comparative matrix in order to validate whether the pair-wise comparison matrix provides a completely consistent evaluation. The final step is to derive the consistency index and consistency ratio.

The stepwise procedure of AHP is presented as follows:

Step 1: Construct the structural hierarchy,

Step 2: Construct the pair-wise comparison matrix,

Assuming $\mathrm{n}$ attributes, the pairwise comparison of attribute $\mathrm{i}$ with attribute $\mathrm{j}$ yields a square matrix $A_{n \times n}$ where $a_{i j}$ denotes the comparative importance of attribute $\mathrm{i}$ with respect to attribute $\mathrm{j}$. In the matrix, $a_{i j}=1$ when $\mathrm{i}=\mathrm{j}$ and $a_{j i}=1 / \mathrm{a}_{i j}$.

$$
\begin{gathered}
\text { Attribute } \\
1 \\
2 \\
3 \\
3 \\
\ldots \\
\ldots \\
n
\end{gathered}\left[\begin{array}{cccccc}
a_{11} & a_{12} & a_{13} & \ldots . & \ldots . & a_{1 n} \\
a_{21} & a_{22} & a_{23} & \ldots . & \ldots . & a_{2 n} \\
a_{31} & a_{32} & a_{33} & \ldots . & \ldots . & a_{3 n} \\
\ldots . & \ldots . & \ldots . & \ldots . & \ldots . & \ldots . \\
\ldots . & \ldots . & \ldots . & \ldots . & \ldots . & \ldots . \\
a_{n 1} & a_{n 2} & r_{n 3} & \ldots . & \ldots . & a_{n n}
\end{array}\right]
$$

Step 3: Construct normalized decision matrix,

$$
c_{i j}=\frac{a_{i j}}{\sum_{I=1}^{n} a_{i j}} i=1,2,3, \ldots \ldots ., n ; j=1,2,3, \ldots \ldots . ., n
$$

Step 4: Construct the weighted normalized decision matrix

$$
\begin{aligned}
& w_{i}=\frac{1}{n} \sum_{J=1}^{n} c_{i j} i=1,2,3, \ldots \ldots ., n \\
& W=\left[w_{1}, \cdots, w_{n}\right]^{T}
\end{aligned}
$$

Step 5: Calculate Eigenvector \& Row matrix

$$
\begin{aligned}
& E=N^{\text {th }} \text { rootvalue } / \sum N^{\text {th }} \text { rootvalue } \\
& \text { Rowmatrix }=\sum_{j=1}^{n} a_{i j} \times e_{j 1}
\end{aligned}
$$


Step 6: Calculate the maximum Eigen value $\lambda_{\max }$.

$$
\lambda_{\max }=\text { Rowmatrix } / E
$$

Step 7: Calculate the consistency index \& consistency ratio.

$$
\begin{gathered}
C I=\left(\lambda_{\max }-n\right) /(n-1) \\
C R=C I / R I
\end{gathered}
$$

where n \& RI denote order of matrix \& Randomly Generated Consistency Index respectively.

\subsection{Fuzzy extended AHP (FAHP)}

\subsubsection{Essences of fuzzy AHP}

The analytic hierarchy process (AHP) is a multiple criteria decision making tool for organizing and analyzing complex decisions and firstly developed by Saaty (1980). Although the AHP is to capture the expert's knowledge, Davoudi and Shykhvand (2012) stated that due to the uncertainty in the judgments of participants, the crisp pair wise comparison in the conventional AHP is insufficient and imprecise to capture the right judgments. Wang and Chen (2007) considered traditional AHP method as an inadequate tool to express the decision maker's opinion in a comparison of alternatives due to using exact value. AHP method is often criticized due to its use of unbalanced nine-point scale of judgments and its inability to adequately handle the inherent uncertainty and imprecision in the pairwise comparison process (Deng, 1999). As human judgements and preferences are vague and 'not very clear”, “"probably so", "very likely”, these terms of expression are very common in decision making, precise numerical values seem to be inadequate to solve real world problems. As some of the evaluation criteria are subjective and qualitative in nature, fuzzy analytic hierarchy process (FAHP) is developed as an alternative to alleviate the deficiencies of the classical AHP and to ease the adaptation to real life problems through the linguistics variables represented by triangular fuzzy numbers (TFN) as an extension of AHP. According to Özdağoğl and özdağoğlu (2007), the fuzziness of the decision makers is reflected in synthetic extension of classical AHP method that is Fuzzy Analytical Hierarchy Process (FAHP). So, Fuzzy AHP, a variant of AHP, has been considered as an effective tool for reducing vagueness.

The first study with FAHP was carried out by Van Laarhoven and Pedrycz (1983). To extract the weights in different multi criteria comparison environments, a variety of FAHP methods have been widely applied in the literature (Enea \& Piazza, 2004; Milkhailov \& Tsvetinov, 2004; Kahraman et al., 2003; Chang, 1992, 1996; Buckley, 1985; Wang et al., 2005; Xu, 2000; Csutora \& Buckley, 2001). Among various techniques embedded in fuzzy AHP, extent analysis method proposed by Chang (1992, 1996) is a popular approach to determine the weight of criteria (e.g., Kahraman et al. 2004). In this research, Chang's extent analysis method is employed to obtain the weight of criteria.

According to Chen and Pham (2001), classical set theory was not capable to describe and handle many real-world applications for containing precise properties. Fuzzy sets are a generalization of conventional set theory that was introduced by Zadeh (1965) as a mathematical way to represent vagueness in everyday life. In order to aid decision making process having human subjectivity, this theory offers effective computational tools to view the problem of modeling uncertainty in a new way. 
Thus the vague data may be represented by fuzzy numbers. If a fuzzy set is convex and normalized, and its membership function is defined in R and piecewise continuous, it is called as "fuzzy number".

So, we have to underscore the use of different fuzzy numbers depending on different situations. Such a situation in practice is intended to use specially triangular and trapezoidal fuzzy numbers of which it is often convenient to work with triangular fuzzy numbers (TFNs) due to easiness in computational procedures. In this paper, TFNs are recommended in order to represent the linguistic variables. Fig. 2. shows the structure of a triangular fuzzy number.

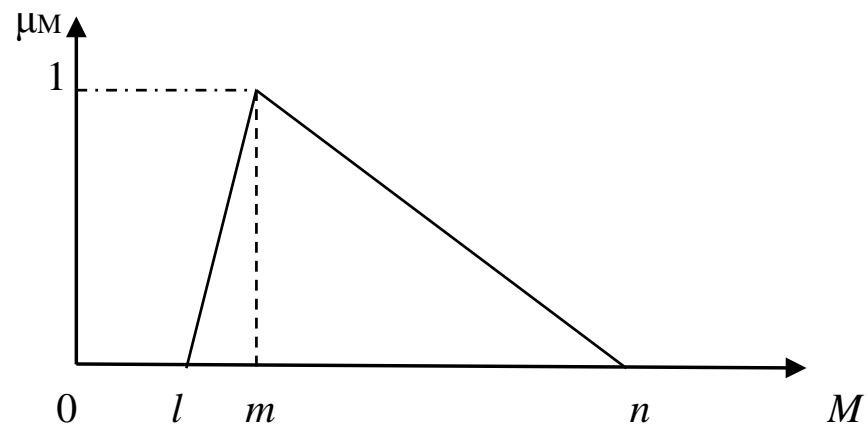

Fig.2. Triangular fuzzy number (M)

Among various operations on triangular fuzzy numbers three important operations are used in this paper. Let $M_{1}=\left(a_{1}, b_{1}, c_{1}\right)$ and $M_{2}=\left(a_{2}, b_{2}, c_{2}\right)$ be two positive triangular fuzzy numbers, the basic operations of triangular fuzzy numbers are defined as follows (Kaufmann \& Gupta, 1991):

$$
\begin{aligned}
& M_{1} \oplus M_{2}=\left(a_{1}+a_{2}, b_{1}+b_{2}, c_{1}+c_{2}\right) \\
& M_{1} \otimes M_{2}=\left(a_{1} \cdot a_{2}, b_{1} \cdot b_{2}, c_{1} \cdot c_{2}\right) \\
& M_{1}^{-1} \approx\left(1 / c_{1}, 1 / b_{1}, 1 / a_{1}\right)
\end{aligned}
$$

In this study, linguistic terms are used to represent the experts' assessments which are converted into 1-9. Saaty’s 1-9 scale can be seen in Table 1.

\section{Table 1}

Saaty's pair-wise comparison scale

\begin{tabular}{ll}
\hline Fuzzv number & Linguistic scale for importance \\
\hline 1 & Eauallv Imbortant \\
3 & Weaklv Important \\
5 & Stronglv Important \\
7 & Verv stronglv Important \\
9 & Extremelv Important \\
2.4 .6 .8 & Intermediate value between adiacent scales \\
\hline
\end{tabular}

\subsubsection{The methodology of FAHP}

In this study, the extent FAHP introduced by Chang $(1992,1996)$ is utilized for handling pair-wise comparison scale on the basis of triangular fuzzy numbers (TFNs). Let $X=\left\{x_{1}, x_{2}, \ldots \ldots \ldots, x_{n}\right\}$ an object set, and $U=\left\{u_{1}, u_{2}, \ldots \ldots \ldots, u_{n}\right\}$ be a goal set. As per Chang $(1992,1996)$ then each object is taken and extent analysis for each goal is performed respectively. Therefore, m extent analysis values for each object can be obtained, with the following signs: 
$M_{g i}^{1}, M_{g i}^{2}, \ldots, M_{g i}^{m}, \quad i=1,2, \ldots, n$

Where $M_{g i}^{j}(j=1,2, \ldots, m)$ are TFNs and represented as $(a, b, c)$. The stepwise procedure of Chang's extent analysis (Chang, 1992, 1996) for implementing FAHP is presented as follows:

Step 1: Define the value of fuzzy synthetic extent,

$$
S_{i}=\sum_{j=1}^{m} M_{g i}^{j} \otimes\left\lceil\sum_{i=1}^{n} \sum_{j=1}^{m} M_{g i}^{j}\right]^{-1}
$$

By using the fuzzy addition operation of $m$ extent analysis values $\sum_{j=1}^{m} M_{g i}^{j}$, is attained such as

$$
\sum_{j=1}^{m} M_{g i}^{j}=\left(\sum_{j=1}^{m} a_{j,} \sum_{j=1}^{m} b_{j,} \sum_{j=1}^{m} c_{j}\right)
$$

to obtain $\left[\sum_{j=1}^{n} \sum_{j=1}^{m} M_{g i}^{j}\right]^{-1}$, the fuzzy addition operation of $M_{g i}^{j}(j=1,2, \ldots, m)$ values is performed such as

$$
\sum_{i=1}^{n} \sum_{i=1}^{m} M_{g i}^{j}=\left(\sum_{i=1}^{n} a_{j,} \sum_{i=1}^{n} b_{j,} \sum_{i=1}^{n} c_{j}\right)
$$

Employing following Eq. inverse of the vector above is calculated.

$$
\left\lceil\sum_{i=1}^{n} \sum_{j=1}^{m} M_{g i}^{j}\right]^{-1}=\left(\frac{1}{\sum_{i=1}^{n} c_{i}}, \frac{1}{\sum_{i=1}^{n} b_{i}}, \frac{1}{\sum_{i=1}^{n} a_{i}}\right)
$$

Step 2: The degree of possibility of supremacy $M_{2}=\left(a_{2}, b_{2}, c_{2}\right) \geq M_{1}=\left(a_{1}, b_{1}, c_{1}\right)$ of two TFNs is stated as

$$
V\left(M_{2} \geq M_{1}\right)=\sup \left[\min \left(\mu_{M_{1}}(x), \mu_{M_{2}}(y)\right)\right]
$$

and can be equivalently expressed as follows:

$$
\begin{aligned}
& V\left(M_{2} \geq M_{1}\right)=h g t\left(M_{1} \cap M_{2}\right)=\mu_{M_{2}}(d) \\
& \mu_{M_{2}}(d)=\left\{\begin{array}{cc}
1 & \text { if } b_{2} \geq b_{1} \\
0 & \text { if } a_{1} \geq c_{2} \\
\frac{a_{1}-c_{2}}{\left(b_{2}-c_{2}\right)-\left(b_{1}-a_{1}\right)} & \text { otherwise }
\end{array}\right.
\end{aligned}
$$

Fig. 3. (Chang, 1996) illustrates Eq. (14) where $d$ is the ordinate of the highest intersection point $D$ between $\mu_{M_{1}}$ and $\mu_{M_{2}}$. To compare $M_{1}$ and $M_{2}$, we need both the values of $V\left(M_{1} \geq M_{2}\right)$ and $V\left(M_{2} \geq M_{1}\right)$. 




Fig. 3. The intersection between $M_{1}$ and $M_{2}$

Step 3: The degree of possibility for a convex fuzzy number to be greater than $k$ convex fuzzy $M_{i}(i=1,2, \ldots \ldots ., k)$ numbers can be defined by

$V\left(M \geq M_{1}, M_{2} \ldots \ldots ., M_{k}\right)=V\left[\left(M \geq M_{1}\right)\right.$ and $\left(M \geq M_{2}\right)$ and $\ldots \ldots \ldots$ and $\left.\left(M \geq M_{k}\right)\right]$ $=\min V\left(M \geq M_{i}\right), \quad i=1,2, \ldots \ldots ., k$

Assuming that $d\left(A_{i}\right)=\min V\left(S_{i} \geq S_{k}\right)$ for $k=1,2, \ldots \ldots, n ; k \neq i$. Then the weight vector is given by

$W^{\prime}=\left(d^{\prime}\left(A_{1}\right), d^{\prime}\left(A_{2}\right), \ldots \ldots, d^{\prime}\left(A_{n}\right)\right)^{T}$

where $A_{i}(i=1,2, \ldots \ldots . ., n)$ are n elements.

Step 4: Finally, calculate the normalized weight vectors employing the following Eq.

$$
W=\left(d\left(A_{1}\right), d\left(A_{2}\right), \ldots \ldots \ldots, d\left(A_{n}\right)\right)^{T}
$$

where $W$ is a non-fuzzy number.

\subsection{Ranking alternatives by TOPSIS}

For the assessment of teaching staff selection, one of the MCDM methods named TOPSIS has been anticipated in this research. In this section, TOPSIS method is explained.

\subsubsection{Computational procedure of TOPSIS}

TOPSIS (Technique for Order Preference by Similarity to Ideal Solution), developed by Hwang and Yoon (1981), is one of the MCDA/MCDM methods for resolving real-world decision problems satisfactorily. Being a simple ranking method in conception and application, it attempts to choose the best alternative that simultaneously has the shortest distance from the positive ideal solution and the farthest distance from the negative-ideal solution. Different researchers defined the positive ideal solution as a solution that maximizes the benefit criteria and minimizes the cost criteria, whereas the negative ideal solution is just opposite to previous one (Wang \& Chang, 2007; Wang \& Elhag, 2006; Wang \& Lee, 2007). Actually the positive ideal solution is composed of all best values attainable of criteria, whereas the negative ideal solution consists of all worst values attainable of criteria. TOPSIS provides a cardinal ranking of alternatives using attribute information (Chen and Hwang, 1992; Yoon \& Hwang, 1995). In TOPSIS method, precise scores that each alternative receives from all the criteria are used in the formation of a decision matrix and normalized decision matrix. By taking into consideration the rates of all attributes, positive and negative ideal solutions are found. By comparing the distance coefficient of each alternative, the preference order of the alternatives is determined. 
The stepwise procedure of Hwang and Yoon (1981) for implementing TOPSIS is presented as follows:

Step 1: Construct normalized decision matrix of beneficial and non-beneficial criteria.

$$
r_{i j}=\frac{x_{i j}}{\sqrt{\sum_{j=1}^{J} x_{i j}^{2}}}, j=1,2,3, \ldots \ldots \ldots . ., J ; i=1,2,3, \ldots \ldots \ldots, n
$$

where $x_{i j}$ and $r_{i j}$ are original and normalized score of decision matrix respectively.

Step 2: Construct the weighted normalized decision matrix by multiplying the weights $w_{i}$ of evaluation criteria with the normalized decision matrix $r_{i j}$.

$$
v_{i j}=w_{j} * r_{i j}, j=1,2,3, \ldots \ldots ., J, i=1,2,3, \ldots \ldots ., n
$$

where $w_{j}$ is the weight for $j$ criterion

Step 3: Determine the positive ideal solution (PIS) and negative ideal solution (NIS)

$$
A^{*}=\left\{v_{1}^{*}, v_{2}^{*}, \ldots \ldots ., v_{n}^{*}\right\} \text { maximum values }
$$

where $v_{i}^{*}=\left\{\max \left(v_{i j}\right)\right.$ if $j \in J ; \min \left(v_{i j}\right)$ if $\left.j \in J^{-}\right\}$

$$
A^{-}=\left\{v_{1}^{-}, v_{2}^{-}, \ldots \ldots . ., v_{n}^{-}\right\} \text {minimum values }
$$

where $v^{-}=\left\{\min \left(v_{i j}\right)\right.$ if $j \in J ; \max \left(v_{i j}\right)$ if $\left.j \in J^{-}\right\}$

Step 4: Calculate the separation measures of each alternative from PIS and NIS

$$
\begin{aligned}
& d_{i}^{*}=\sqrt{\sum_{j=1}^{n}\left(v_{i j}-v_{j}^{*}\right)^{2}}, j=1,2, \ldots \ldots ., J \\
& d_{i}^{-}=\sqrt{\sum_{j=1}^{n}\left(v_{i j}-v_{j}^{-}\right)^{2}}, i=1,2, \ldots \ldots . ., J
\end{aligned}
$$

Step 5: Calculate the relative closeness coefficient to the ideal solution of each alternative

$$
C C_{i}=\frac{d_{i}^{-}}{d_{i}^{*}+d_{i}^{-}}, i=1,2, \ldots \ldots, J
$$

Step 6: Based on the decreasing values of closeness coefficient, alternatives are ranked from most valuable to worst. The alternative having highest closeness coefficient $\left(C C_{i}\right)$ is selected.

\section{Case study}

The model has been applied in a particular department of a public engineering university of Bangladesh 
for identifying the right personnel among seven applicants who applied for the same post. The reason why educational sector is chosen is, the existing recruitment process isn't adequate to take the right decisions. To preserve confidentiality, the name of the university and seven applicants have been kept undisclosed and the seven applicants are referenced as $T_{1}, T_{2}, T_{3}, T_{4} T_{5}, T_{6}$ and $T_{7}$. The university desires to decide which candidate among the seven applicants should be selected based on its vision and strategy.

In the decision process, data are collected from both recruitment panel and university students. They all attach importance to the quality of the service in educational sector. First of all, the evaluation criteria for the selection decision were taken from the studies in the literature and the discussions with the experts in specific sector. The hierarchy of the decision model having five main-criteria and 15 subcriteria is constructed in Table 2.

\section{Table 2}

Hierarchical Representation of Criteria

Criteria

\begin{tabular}{|c|c|c|}
\hline & & Subject Knowledge $\left(\mathrm{C}_{1}\right)$ \\
\hline & & Ability of communication $\left(\mathrm{C}_{2}\right)$ \\
\hline & Main Criteria & Discipline $\left(\mathrm{C}_{3}\right)$ \\
\hline & & Co-operative $\left(\mathrm{C}_{4}\right)$ \\
\hline & & Creative $\left(\mathrm{C}_{5}\right)$ \\
\hline & & Ability of teaching $\left(\mathrm{C}_{11}\right)$ \\
\hline & Subject Knowledge $\left(\mathrm{C}_{1}\right)$ & Understand student psychology $\left(\mathrm{C}_{12}\right)$ \\
\hline & & Problem solving capability ( $\left.\mathrm{C}_{13}\right)$ \\
\hline & & Clear idea $\left(\mathrm{C}_{21}\right)$ \\
\hline & Ability of commutation $\left(\mathrm{C}_{2}\right)$ & Accessibility ( $\left.\mathrm{C}_{22}\right)$ \\
\hline & & Power of explanation $\left(\mathrm{C}_{23}\right)$ \\
\hline & & Fair (C31) \\
\hline Sub Criteria & Discipline $\left(\mathrm{C}_{3}\right)$ & Attitude $\left(\mathrm{C}_{32}\right)$ \\
\hline & & Well organized $\left(\mathrm{C}_{33}\right)$ \\
\hline & & Good guidance $\left(\mathrm{C}_{41}\right)$ \\
\hline & Co-operative $\left(\mathrm{C}_{4}\right)$ & Dedicated $\left(\mathrm{C}_{42}\right)$ \\
\hline & & Power of motivation $\left(\mathrm{C}_{43}\right)$ \\
\hline & & Positive reinforcement $\left(\mathrm{C}_{51}\right)$ \\
\hline & Creative (C5) & Passionate ( $\left.\mathrm{C}_{52}\right)$ \\
\hline & & Inspirational $\left(\mathrm{C}_{53}\right)$ \\
\hline
\end{tabular}

The weights of the main criteria considering the decision makers' subjective judgments are estimated by using AHP and FAHP methods. In order to reduce the uncertainty and vagueness in the decision process, the pair-wise comparison scores have been proposed by three decision makers for determining the weights of the main criteria and the sub-criteria by using Saaty's 1-9 scale (Chen, 2004). Then, an aggregated fuzzy pair-wise comparison matrix is constructed by integrating three decision makers' grades by using Eq. (18) (Chen, Lin, \& Huang, 2006) while in AHP approach it is done by average method. A pair-wise comparison matrix for the main-criteria and the calculation of the weights under AHP is given as follows. 
A normalized matrix, C has been calculated by using Eq. (1):

$$
C=\left[\begin{array}{lllll}
1.00 & 5.00 & 7.00 & 3.00 & 5.00 \\
0.20 & 1.00 & 5.00 & 1.00 & 5.00 \\
0.14 & 0.20 & 1.00 & 0.33 & 3.00 \\
0.33 & 1.00 & 3.00 & 1.00 & 5.00 \\
0.20 & 0.20 & 0.33 & 0.20 & 1.00
\end{array}\right]
$$

Then the priority weights are calculated by using Eq. (2):

$$
w_{1}=2.44 \times 1 / 5=0.49 \quad w_{2}=0.99 \times 1 / 5=0.20 \quad w_{3}=0.38 \times 1 / 5=0.08 \quad w_{4}=0.94 \times 1 / 5=0.19 \quad w_{5}=0.24 \times 1 / 5=0.05
$$

The normalized weight vector respect to main criteria is $W=(0.49,0.20,0.08,0.19,0.05)$. The same computational ways are anticipated to determine the weights of the sub-criteria $\left(w_{i}\right)$ which are presented in Table 3. Consistency ratio (CR) has been calculated using defined formula and it is less than $10 \%$.

\section{Table 3}

Weights of sub-criteria

\begin{tabular}{cccc}
\hline Sub-criteria & Weight & Sub-criteria & Weight \\
\hline$C_{11}$ & 0.28 & $C_{33}$ & 0.08 \\
$C_{12}$ & 0.64 & $C_{41}$ & 0.28 \\
$C_{13}$ & 0.07 & $C_{42}$ & 0.64 \\
$C_{21}$ & 0.63 & $C_{43}$ & 0.07 \\
$C_{22}$ & 0.11 & $C_{51}$ & 0.07 \\
$C_{23}$ & 0.26 & $C_{52}$ & 0.28 \\
$C_{31}$ & 0.19 & $C_{53}$ & 0.64 \\
$C_{32}$ & 0.72 & & \\
\hline
\end{tabular}

Now, the authors have applied fuzzy extended AHP (FAHP) to calculate the weights of selection criteria. Fuzzy pair-wise comparison matrix for main-criteria is presented in Table 4.

\section{Table 4}

Aggregated fuzzy pair-wise comparison matrix

\begin{tabular}{llllll}
\hline & $C_{1}$ & $C_{2}$ & $C_{3}$ & $C_{4}$ & $C_{5}$ \\
\hline$C_{1}$ & $(1,1,1)$ & $(0.14,3.38,5)$ & $(3,5,7)$ & $(0.14,1.11,3)$ & $(5,7,9)$ \\
$C_{2}$ & $(0.2,2.47,7)$ & $(1,1,1)$ & $(0.2,3.40,5)$ & $(0.2,2.73,7)$ & $(1,4.33,7)$ \\
$C_{3}$ & $(1.40,0.22,0.33)$ & $(0.20,1.80,5)$ & $(1,1,1)$ & $(0.20,2.51,7)$ & $(0.2,0.73,5)$ \\
$C_{4}$ & $(0.33,4.11,7)$ & $(0.14,2.05,5)$ & $(0.14,2.71,5)$ & $(1,1,1)$ & $(5,5.67,7)$ \\
$C_{5}$ & $(0.11,0.15,0.20)$ & $(0.14,0.45,1)$ & $(0.20,2.67,5)$ & $(0.14,0.17,0.2)$ & $(1,1,1)$ \\
\hline
\end{tabular}

The calculations of the weights are given as follows.

The values of fuzzy synthetic extent are calculated by using Eq. (9). 
$S_{c_{1}}=(11.29,15.94,23) \otimes(1 / 106.86,1 / 64.58,1 / 23.76)=(0.11,0.25,0.97)$

$S_{C_{2}}=(2.60,18.20,31) \otimes(1 / 106.86,1 / 64.58,1 / 23.76)=(0.02,0.28,1.30)$

$S_{C_{3}}=(1.69,8.87,18.33) \otimes(1 / 106.86,1 / 64.58,1 / 23.76)=(0.02,0.14,0.77)$

$S_{c_{4}}=(6.62,17.27,27) \otimes(1 / 106.86,1 / 64.58,1 / 23.76)=(0.06,0.27,1.14)$

$S_{C_{5}}=(1.57,4.29,7.34) \otimes(1 / 106.86,1 / 64.58,1 / 23.76)=(0.01,0.07,0.31)$

The degree of possibility of supremacy of each criterion over another denoting by $V\left(S_{c_{i}} \geq\right.$ $S_{c_{j}}$ where $\left.i=1,2,3,4,5 ; j=1,2,3,4,5\right)$. The obtained synthetic values are compared by using Eq. (15) and the following results are obtained:

$$
\begin{array}{cccc}
V\left(S_{C_{1}} \geq S_{C_{2}}\right)=1.00 & V\left(S_{C_{1}} \geq S_{C_{3}}\right)=1.00 & V\left(S_{C_{1}} \geq S_{C_{4}}\right)=1.00 & V\left(S_{C_{1}} \geq S_{C_{5}}\right)=1.00 \\
V\left(S_{C_{2}} \geq S_{C_{1}}\right)=0.95 & V\left(S_{C_{2}} \geq S_{C_{3}}\right)=1.00 & V\left(S_{C_{2}} \geq S_{C_{4}}\right)=0.97 & V\left(S_{C_{2}} \geq S_{C_{5}}\right)=1.00 \\
V\left(S_{C_{3}} \geq S_{C_{1}}\right)=0.86 & V\left(S_{C_{3}} \geq S_{C_{2}}\right)=0.90 & V\left(S_{C_{3}} \geq S_{C_{4}}\right)=0.86 & V\left(S_{C_{3}} \geq S_{C_{5}}\right)=1.00 \\
V\left(S_{C_{4}} \geq S_{C_{1}}\right)=0.96 & V\left(S_{C_{4}} \geq S_{C_{2}}\right)=1.00 & V\left(S_{C_{4}} \geq S_{C_{3}}\right)=1.00 & V\left(S_{C_{4}} \geq S_{C_{5}}\right)=1.00 \\
V\left(S_{C_{5}} \geq S_{C_{1}}\right)=0.53 & V\left(S_{C_{5}} \geq S_{C_{2}}\right)=0.66 & V\left(S_{C_{5}} \geq S_{C_{3}}\right)=0.83 & V\left(S_{C_{5}} \geq S_{C_{4}}\right)=0.59
\end{array}
$$

Then the priority weights are calculated by using Eq. (16):

$$
\begin{array}{ll}
d^{\prime}\left(C_{1}\right)=\min (1.00,1.00,1.00,1.00)=1.00 & d^{\prime}\left(C_{2}\right)=\min (0.95,1.00,0.97,1.00)=0.95 \\
d^{\prime}\left(C_{3}\right)=\min (0.83,0.90,0.86,1.00)=0.83 & d^{\prime}\left(C_{4}\right)=\min (0.96,1.00,1.00,1.00)=0.96 \\
d^{\prime}\left(C_{5}\right)=\min (0.53,0.66,0.83,0.59)=0.53 &
\end{array}
$$

The weight vector forms $(1.00,0.95,0.83,0.96,0.53)$. After the normalization, weight vector of the main criteria $(1.00,0.95,0.83,0.96,0.53)$ is transformed into the normalized weight vector with respect to the main criteria as $W=(0.2336,0.2220,0.1936,0.2265,0.1242)$. The same computational ways are anticipated to determine the weights of the sub-criteria $\left(w_{i}\right)$ which are presented in Table 5 . The normalized weight vector for AHP \& FAHP methods respect to main goal is portrayed in Fig.4. According to Fig.4, the most important criteria under both methods are "Subject Knowledge" in the decision makers' subjective judgments which are followed by the others.

\section{Table 6}

Weights of sub-criteria by FAHP

\begin{tabular}{cccc}
\hline Sub-criteria & Weight & Sub-criteria & Weight \\
\hline$C_{11}$ & 0.33 & $C_{33}$ & 0.33 \\
$C_{12}$ & 0.34 & $C_{41}$ & 0.34 \\
$C_{13}$ & 0.33 & $C_{42}$ & 0.32 \\
$C_{21}$ & 0.50 & $C_{43}$ & 0.34 \\
$C_{22}$ & 0.19 & $C_{51}$ & 0.31 \\
$C_{23}$ & 0.31 & $C_{52}$ & 0.35 \\
$C_{31}$ & 0.33 & $C_{53}$ & 0.34 \\
$C_{32}$ & 0.34 & & \\
\hline
\end{tabular}


As indicated before, one of the well-known MCDM methods named TOPSIS method is used to rank the potential alternatives considering the weights of all criteria which are obtained by AHP \& FAHP methods. In the first step of the algorithm, a decision matrix using 3 decision makers' opinion $\left(D_{1}, D_{2}\right.$, $D_{3}$ ) is developed using numerical values. The decision matrix of TOPSIS method is shown in Table 7.

Table 7

Decision matrix using linguistics variables

\begin{tabular}{|c|c|c|c|c|c|c|c|c|c|c|c|c|c|c|c|c|c|c|c|c|c|}
\hline & \multicolumn{3}{|l|}{$\mathrm{T}_{1}$} & \multicolumn{3}{|l|}{$\mathrm{T}_{2}$} & \multicolumn{2}{|l|}{$T_{3}$} & \multicolumn{3}{|c|}{$\mathrm{T}_{4}$} & \multicolumn{3}{|c|}{$\mathrm{T}_{5}$} & \multicolumn{3}{|c|}{$\mathrm{T}_{6}$} & \multicolumn{3}{|c|}{$\mathrm{T}_{7}$} & \\
\hline & $\mathrm{D}_{1}$ & $\mathrm{D}_{2}$ & $\mathrm{D}_{3}$ & $\mathrm{D}_{1}$ & $\mathrm{D}_{2}$ & $D_{1}$ & $\mathrm{D}_{1}$ & $\mathrm{D}_{2}$ & $\mathrm{D}_{3}$ & $\mathrm{D}_{2}$ & $\mathrm{D}_{3}$ & $\mathrm{D}_{3}$ & $\mathrm{D}_{1}$ & $\mathrm{D}_{2}$ & $\mathrm{D}_{3}$ & $\mathrm{D}_{1}$ & $\mathrm{D}_{2}$ & $\mathrm{D}_{3}$ & $\mathrm{D}_{1}$ & $\mathrm{D}_{2}$ & $\mathrm{D}_{3}$ \\
\hline $\mathrm{C}_{1}$ & VG & VG & $G$ & $G$ & M & M & M & $F$ & M & V & $G$ & $F$ & $\mathrm{D}$ & $F$ & MP & $G$ & M & MP & $G$ & VG & $\mathrm{F}$ \\
\hline $\mathrm{C}_{1}$ & $G$ & $G$ & M & MP & $\mathrm{M}$ & $G$ & M & $\mathrm{F}$ & $G$ & $P$ & $G$ & $\Gamma$ & VP & MP & $\mathrm{F}$ & M & $\mathrm{F}$ & $P$ & MP & $\mathrm{F}$ & $P$ \\
\hline $\mathrm{C}_{1}$ & $G$ & $G$ & $\mathrm{VG}$ & M & MP & $\mathrm{M}$ & M & $F$ & $F$ & $\mathrm{M}$ & M & $G$ & $P$ & MP & M & $G$ & M & $F$ & M & $P$ & $F$ \\
\hline $\mathrm{C}_{2}$ & M & $G$ & M & $G$ & F & M & $F$ & MP & P & $G$ & M & MP & $P$ & MP & F & $G$ & $F$ & MP & M & VG & MP \\
\hline $\mathrm{C}_{2}$ & $G$ & $\mathrm{VG}$ & M & $F$ & $F$ & MP & MP & MP & $F$ & $G$ & $P$ & M & $F$ & MP & $G$ & $G$ & $F$ & $P$ & MP & $G$ & $F$ \\
\hline $\mathrm{C}_{2}$ & M & $\mathrm{F}$ & $\mathrm{G}$ & $F$ & MP & $\mathrm{F}$ & $G$ & M & $\mathrm{G}$ & $P$ & MP & $G$ & M & $G$ & $\mathrm{~F}$ & $G$ & $P$ & MP & M & VG & MP \\
\hline $\mathrm{C}_{3}$ & $F$ & MP & $G$ & $F$ & $\mathrm{~F}$ & $\mathrm{~F}$ & $F$ & M & M & $P$ & MP & $G$ & VG & $G$ & MP & $P$ & $G$ & M & VG & MP & $\mathrm{F}$ \\
\hline $\mathrm{C}_{3}$ & MP & MP & $\mathrm{F}$ & MP & MP & $G$ & $F$ & $F$ & M & $P$ & VP & $G$ & VG & $G$ & M & MP & $G$ & $P$ & $\mathrm{~F}$ & $\mathrm{VG}$ & $G$ \\
\hline $\mathrm{C}_{3}$ & M & $F$ & $G$ & $\mathrm{VG}$ & VP & $G$ & $F$ & $\mathrm{~F}$ & M & $G$ & M & $\mathrm{F}$ & MP & $G$ & $P$ & $F$ & M & $G$ & $P$ & MP & $G$ \\
\hline $\mathrm{C}_{4}$ & $\mathrm{G}$ & VG & $\mathrm{G}$ & M & $\mathrm{M}$ & M & MP & $F$ & MP & $G$ & $P$ & M & VP & $F$ & $G$ & MP & $G$ & M & $\mathrm{P}$ & $\mathrm{M}$ & VP \\
\hline $\mathrm{C}_{4}$ & $G$ & $G$ & VG & $F$ & M & $F$ & $\mathrm{~F}$ & $\mathrm{G}$ & $F$ & V & MP & M & $P$ & $G$ & MP & $F$ & $\mathrm{VG}$ & M & $G$ & VP & $P$ \\
\hline $\mathrm{C}_{4}$ & M & $G$ & $\mathrm{~F}$ & $\mathrm{VG}$ & $\mathrm{VG}$ & $G$ & MP & $F$ & MP & $G$ & M & P & VP & MP & $\mathrm{F}$ & $F$ & $G$ & VG & $G$ & MP & $\mathrm{M}$ \\
\hline $\mathrm{C}_{5}$ & $\mathrm{~F}$ & $F$ & M & $V G$ & $\mathrm{VG}$ & $\mathrm{VG}$ & $\mathrm{F}$ & $\mathrm{F}$ & MP & $P$ & $\mathrm{~F}$ & MP & $G$ & M & VP & VP & MP & $P$ & M & $\mathrm{VG}$ & MP \\
\hline $\mathrm{C}_{5}$ & $G$ & $\mathrm{G}$ & $\mathrm{F}$ & M & $\mathrm{VG}$ & M & MP & MP & MP & $\mathrm{P}$ & VG & $G$ & $\mathrm{~F}$ & MP & $\mathrm{F}$ & $G$ & VP & $\mathrm{P}$ & VG & $P$ & $\mathrm{~F}$ \\
\hline $\mathrm{C}_{5}$ & $\mathrm{G}$ & M & MP & $F$ & $P$ & MP & $\mathrm{VG}$ & M & $F$ & M & $G$ & $F$ & $P$ & VP & M & $F$ & $V G$ & $G$ & M & $\mathrm{M}$ & $P$ \\
\hline
\end{tabular}

Then, the aggregated values of each sub-criterion are calculated by using average technique in TOPSIS method as shown in Table 8.

Table 8

Aggregated decision matrix of TOPSIS method

\begin{tabular}{llllllllllllllll}
\hline & $\mathrm{C}_{11}$ & $\mathrm{C}_{12}$ & $\mathrm{C}_{13}$ & $\mathrm{C}_{21}$ & $\mathrm{C}_{22}$ & $\mathrm{C}_{23}$ & $\mathrm{C}_{31}$ & $\mathrm{C}_{32}$ & $\mathrm{C}_{33}$ & $\mathrm{C}_{41}$ & $\mathrm{C}_{42}$ & $\mathrm{C}_{43}$ & $\mathrm{C}_{51}$ & $\mathrm{C}_{52}$ & $\mathrm{C}_{53}$ \\
\hline $\mathrm{T}_{1}$ & 8.33 & 7.33 & 7.66 & 7.66 & 8 & 7 & 6 & 5.33 & 7 & 7.66 & 7.66 & 7 & 6.66 & 6.66 & 6.66 \\
$\mathrm{~T}_{2}$ & 7.66 & 6.66 & 7 & 7 & 5.66 & 5.66 & 6 & 5.66 & 6.33 & 8 & 6.66 & 8.33 & 9 & 8.33 & 5 \\
$\mathrm{~T}_{3}$ & 7.33 & 7 & 6.66 & 5 & 5.33 & 7.33 & 7.33 & 6.66 & 6.66 & 5.33 & 6.33 & 5.33 & 5.66 & 5 & 7.66 \\
$\mathrm{~T}_{4}$ & 7.33 & 5.66 & 6.66 & 6.66 & 6.33 & 5.33 & 5.33 & 4.66 & 7 & 6.33 & 7.33 & 6.33 & 5 & 6.66 & 6 \\
$\mathrm{~T}_{5}$ & 5 & 4.66 & 5.66 & 5 & 6 & 7 & 7 & 8 & 5.33 & 5.33 & 5.33 & 4.66 & 6 & 5.66 & 5 \\
$\mathrm{~T}_{6}$ & 6.66 & 6 & 7 & 6 & 5.66 & 5.33 & 6.33 & 5.33 & 7 & 5.66 & 7.66 & 7.33 & 4 & 4.66 & 7.33 \\
$\mathrm{~T}_{7}$ & 7.33 & 5 & 6 & 7.33 & 6 & 7.33 & 6.66 & 7.33 & 5.33 & 5 & 4.66 & 6.66 & 7.33 & 6.33 & 6.66 \\
\hline
\end{tabular}

Then, normalization of these values is made through Eq. (19). Normalized decision matrix is shown in Table 9. While the normalized weight is determined by multiplying each of the normalized decision matrix elements with their weights obtaining from AHP method for each criterion in the AHP-TOPSIS method, the weighted normalized decision matrix is formed in the same computational ways for FAHPTOPSIS method. Then the distance of each alternative from PIS $\left(A^{*}\right)$ and NIS $\left(A^{-}\right)$with respect to each criterion are calculated like in Eqs. (23) \& (24). Afterwards the closeness coefficients $\left(\mathrm{CC}_{\mathrm{i}}\right)$ of seven candidates are calculated with Eq. (25) and the ranking is done in a decreasing order. Calculation steps of the TOPSIS method using weights of AHP and FAHP are given in Table 10 and 11 respectively. 
Table 9

Normalized decision matrix for TOPSIS analysis

\begin{tabular}{llllllllllllllll}
\hline & $\mathrm{C}_{11}$ & $\mathrm{C}_{12}$ & $\mathrm{C}_{13}$ & $\mathrm{C}_{21}$ & $\mathrm{C}_{22}$ & $\mathrm{C}_{23}$ & $\mathrm{C}_{31}$ & $\mathrm{C}_{32}$ & $\mathrm{C}_{33}$ & $\mathrm{C}_{41}$ & $\mathrm{C}_{42}$ & $\mathrm{C}_{43}$ & $\mathrm{C}_{51}$ & $\mathrm{C}_{52}$ & $\mathrm{C}_{53}$ \\
\hline $\mathrm{T}_{1}$ & 0.44 & 0.45 & 0.43 & 0.45 & 0.49 & 0.41 & 0.35 & 0.32 & 0.41 & 0.45 & 0.44 & 0.40 & 0.39 & 0.40 & 0.39 \\
$\mathrm{~T}_{2}$ & 0.40 & 0.41 & 0.40 & 0.41 & 0.35 & 0.33 & 0.35 & 0.34 & 0.37 & 0.47 & 0.38 & 0.48 & 0.53 & 0.50 & 0.29 \\
$\mathrm{~T}_{3}$ & 0.39 & 0.43 & 0.38 & 0.29 & 0.33 & 0.43 & 0.43 & 0.40 & 0.39 & 0.31 & 0.36 & 0.30 & 0.33 & 0.30 & 0.45 \\
$\mathrm{~T}_{4}$ & 0.39 & 0.35 & 0.38 & 0.39 & 0.39 & 0.31 & 0.31 & 0.28 & 0.41 & 0.37 & 0.42 & 0.36 & 0.29 & 0.40 & 0.35 \\
$\mathrm{~T}_{5}$ & 0.26 & 0.29 & 0.32 & 0.29 & 0.37 & 0.41 & 0.41 & 0.48 & 0.31 & 0.31 & 0.30 & 0.27 & 0.35 & 0.34 & 0.29 \\
$\mathrm{~T}_{6}$ & 0.35 & 0.37 & 0.40 & 0.35 & 0.35 & 0.31 & 0.37 & 0.32 & 0.41 & 0.39 & 0.44 & 0.42 & 0.24 & 0.28 & 0.43 \\
$\mathrm{~T}_{7}$ & 0.39 & 0.31 & 0.34 & 0.43 & 0.37 & 0.43 & 0.39 & 0.44 & 0.31 & 0.29 & 0.27 & 0.38 & 0.43 & 0.38 & 0.39 \\
\hline
\end{tabular}

Table 10

Calculation steps of the TOPSIS method using weights of AHP

\begin{tabular}{|c|c|c|c|c|c|c|c|c|c|}
\hline \multicolumn{8}{|c|}{ Weighted normalized values } & \multirow{2}{*}{$P I S\left(A^{+}\right)$} & \multirow{2}{*}{$N I S\left(A^{-}\right)$} \\
\hline & $T_{1}$ & $T_{2}$ & $T_{3}$ & $T_{4}$ & $T_{5}$ & $T_{6}$ & $T_{7}$ & & \\
\hline$C_{11}$ & 0.12 & 0.11 & 0.11 & 0.11 & 0.07 & 0.10 & 0.11 & 0.12 & 0.07 \\
\hline$C_{12}$ & 0.29 & 0.26 & 0.28 & 0.22 & 0.18 & 0.24 & 0.20 & 0.29 & 0.18 \\
\hline$C_{13}$ & 0.03 & 0.03 & 0.03 & 0.03 & 0.02 & 0.03 & 0.02 & 0.03 & 0.02 \\
\hline$C_{21}$ & 0.28 & 0.26 & 0.18 & 0.25 & 0.18 & 0.22 & 0.27 & 0.28 & 0.18 \\
\hline$C_{22}$ & 0.05 & 0.04 & 0.04 & 0.04 & 0.04 & 0.04 & 0.04 & 0.05 & 0.04 \\
\hline$C_{23}$ & 0.11 & 0.09 & 0.11 & 0.08 & 0.11 & 0.08 & 0.11 & 0.11 & 0.08 \\
\hline$C_{31}$ & 0.07 & 0.07 & 0.08 & 0.06 & 0.08 & 0.07 & 0.07 & 0.08 & 0.06 \\
\hline$C_{32}$ & 0.23 & 0.25 & 0.29 & 0.20 & 0.35 & 0.23 & 0.32 & 0.35 & 0.20 \\
\hline$C_{33}$ & 0.03 & 0.03 & 0.03 & 0.03 & 0.03 & 0.03 & 0.03 & 0.03 & 0.03 \\
\hline$C_{41}$ & 0.13 & 0.13 & 0.09 & 0.10 & 0.09 & 0.11 & 0.08 & 0.13 & 0.08 \\
\hline$C_{42}$ & 0.28 & 0.24 & 0.23 & 0.27 & 0.20 & 0.28 & 0.17 & 0.28 & 0.17 \\
\hline$C_{43}$ & 0.03 & 0.03 & 0.02 & 0.02 & 0.02 & 0.03 & 0.03 & 0.03 & 0.02 \\
\hline$C_{51}$ & 0.03 & 0.04 & 0.02 & 0.02 & 0.02 & 0.02 & 0.03 & 0.04 & 0.02 \\
\hline$C_{52}$ & 0.11 & 0.14 & 0.08 & 0.11 & 0.10 & 0.08 & 0.11 & 0.14 & 0.08 \\
\hline$C_{53}$ & 0.25 & 0.19 & 0.29 & 0.22 & 0.19 & 0.28 & 0.25 & 0.29 & 0.19 \\
\hline$d+$ & 0.13 & 0.16 & 0.15 & 0.19 & 0.21 & 0.16 & 0.16 & & \\
\hline$d-$ & 0.21 & 0.17 & 0.18 & 0.14 & 0.15 & 0.16 & 0.17 & & \\
\hline$C C_{i}$ & 0.62 & 0.52 & 0.55 & 0.43 & 0.42 & 0.50 & 0.51 & & \\
\hline
\end{tabular}

Table 11

Calculation steps of the TOPSIS method using weights of FAHP

\begin{tabular}{|c|c|c|c|c|c|c|c|c|c|}
\hline \multicolumn{8}{|c|}{ Weighted normalized values } & \multirow{2}{*}{$P I S\left(A^{+}\right)$} & \multirow{2}{*}{$N I S\left(A^{-}\right)$} \\
\hline & $T_{1}$ & $T_{2}$ & $T_{3}$ & $T_{4}$ & $T_{5}$ & $T_{6}$ & $T_{7}$ & & \\
\hline$C_{11}$ & 0.15 & 0.13 & 0.13 & 0.13 & 0.09 & 0.12 & 0.13 & 0.15 & 0.09 \\
\hline$C_{12}$ & 0.15 & 0.14 & 0.15 & 0.12 & 0.10 & 0.13 & 0.11 & 0.15 & 0.10 \\
\hline$C_{13}$ & 0.14 & 0.13 & 0.12 & 0.12 & 0.11 & 0.13 & 0.11 & 0.14 & 0.11 \\
\hline$C_{21}$ & 0.22 & 0.20 & 0.15 & 0.20 & 0.15 & 0.18 & 0.21 & 0.22 & 0.15 \\
\hline$C_{22}$ & 0.09 & 0.07 & 0.06 & 0.07 & 0.07 & 0.07 & 0.07 & 0.09 & 0.06 \\
\hline$C_{23}$ & 0.13 & 0.10 & 0.13 & 0.10 & 0.13 & 0.10 & 0.13 & 0.13 & 0.10 \\
\hline$C_{31}$ & 0.12 & 0.12 & 0.14 & 0.10 & 0.14 & 0.12 & 0.13 & 0.14 & 0.10 \\
\hline$C_{32}$ & 0.11 & 0.12 & 0.14 & 0.10 & 0.16 & 0.11 & 0.15 & 0.16 & 0.10 \\
\hline$C_{33}$ & 0.14 & 0.12 & 0.13 & 0.14 & 0.10 & 0.14 & 0.10 & 0.14 & 0.10 \\
\hline$C_{41}$ & 0.15 & 0.16 & 0.11 & 0.13 & 0.11 & 0.13 & 0.10 & 0.16 & 0.10 \\
\hline$C_{42}$ & 0.14 & 0.12 & 0.12 & 0.13 & 0.10 & 0.14 & 0.09 & 0.14 & 0.09 \\
\hline$C_{43}$ & 0.14 & 0.16 & 0.10 & 0.12 & 0.09 & 0.14 & 0.13 & 0.16 & 0.09 \\
\hline$C_{51}$ & 0.12 & 0.16 & 0.10 & 0.09 & 0.11 & 0.07 & 0.13 & 0.16 & 0.07 \\
\hline$C_{52}$ & 0.14 & 0.18 & 0.11 & 0.14 & 0.12 & 0.10 & 0.13 & 0.18 & 0.10 \\
\hline$C_{53}$ & 0.13 & 0.10 & 0.15 & 0.12 & 0.10 & 0.15 & 0.13 & 0.15 & 0.10 \\
\hline$d+$ & 0.09 & 0.09 & 0.15 & 0.14 & 0.19 & 0.16 & 0.13 & & \\
\hline$d-$ & 0.17 & 0.18 & 0.12 & 0.11 & 0.09 & 0.12 & 0.14 & & \\
\hline$C C_{i}$ & 0.66 & 0.65 & 0.44 & 0.43 & 0.33 & 0.42 & 0.52 & & \\
\hline
\end{tabular}

In Table 12, selections of the teacher are ranked with respect to both methods. 
Table 12

Ranking of the candidates

\begin{tabular}{ccccc}
\hline Alternatives & \multicolumn{2}{c}{ AHP-TOPSIS } & \multicolumn{2}{c}{ FAHP-TOPSIS } \\
\hline & $C C_{i}$ & Ranking & $C C_{i}$ & Ranking \\
\hline$T_{1}$ & 0.6243 & 1 & 0.6625 & 1 \\
$T_{2}$ & 0.5153 & 3 & 0.6598 & 2 \\
$T_{3}$ & 0.5520 & 2 & 0.4381 & 4 \\
$T_{4}$ & 0.4272 & 6 & 0.4369 & 5 \\
$T_{5}$ & 0.4165 & 7 & 0.3347 & 7 \\
$T_{6}$ & 0.4983 & 5 & 0.4256 & 6 \\
$T_{7}$ & 0.5058 & 4 & 0.5182 & 3 \\
\hline
\end{tabular}

The summarized data about all rankings is given in Fig. 5. The recruitment panel can take decisions from the plot which indicates " $T_{1}$ " as a good choice for consideration.

\section{Results and discussions}

Depending on the values of closeness coefficients of seven applicants, the best ranked alternative for the personnel selection is different with respect to both methods. According to all the calculations, the ranking of the teaching staff in performance is; Candidate 1 with 62\%, in AHP-TOPSIS \& 66\% in FAHP-TOPSIS. Applicant 1 has the best service quality performance among the others. So, universities should improve their service quality considering these criteria that the students care.

\section{Conclusions and future work}

Selecting a better academic staff among the others is very significant as the success of any organization solely depends on how well it selects its manpower. It is a multi-staged decision-making problem having both numerical and qualitative criteria. But the proper way of selecting faculty members for public universities is very rare in Bangladesh. So, this paper has presented the successful implementation of AHP, FAHP \& TOPSIS methods as an effective tool for evaluating performance of various teaching staff in an academic institution. These MCDM methods provide simple \& powerful ways to find out the most desirable alternatives. Therefore, in the future, it is not an option but essential to implement this method for dealing with uncertainty in a variety of multi-criteria decision making problems. The proposed method is also effective in group decision environment study like hospital, manufacturing industry applications etc. where it is found to be difficult to come to a moot point individually. In future studies other models of multi-criteria methods such as ANN or fuzzy MOORA can easily be implemented in similar situations and the results can be compared.

\section{Acknowledgements}

The authors wish to acknowledge the support and assistance provided by the Department of Industrial and Production Engineering, Jessore University of Science and Technology, Bangladesh.

\section{References}

Afshari, A., Mojahed, M., \& Yusuff, R.M. (2010). Simple Additive Weighting approach to Personnel Selection problem. International Journal of Innovation, Management and Technology, 1(5), 511515.

Barber, A.E. (1998). Recruiting employees. Thousand Oaks. CA: Sage Publications.

Becker, G. S. (1995). Human capital and poverty alleviation. World Bank, Human Resources Development and Operations policy. 
Buckley, J. J. (1985). Fuzzy hierarchical analysis. Fuzzy Sets and Systems, 17, 233-247.

Capaldo, G., Zollo, G. (1992). Applying fuzzy logic to staff assessment: a case study. The International Journal of Management Science, 29, 585-597.

Chang, D.Y. (1992). Extent analysis and synthetic decision. Optimization Techniques and Applications, 1, 352-355.

Chang, D.Y. (1996). Applications of the extent analysis method on fuzzy AHP. European Journal of Operational Research, 95(3), 649-655.

Chen, C. T., Lin, C. T., \& Huang, S. F. (2006). A fuzzy approach for supplier evaluation and selection in supply chain management. International Journal of Production Economics, 102, 289-301.

Chen, G., \& Pham, T. T. (2001). Introduction to fuzzy, sets fuzzy, logic and fuzzy control systems. Florida: CRC Press.

Chen, H. (2004). A research based on fuzzy AHP for multi-criteria supplier selection in supply chain. Master thesis, National Taiwan University of Science and Technology, Department of Industrial Management.

Chen, P. C. (2009). A Fuzzy Multiple Criteria Decision Making Model in Employee Recruitment”, IJCSNS International Journal of Computer Science and Network Security, 9 (7), 113-117.

Chen, S. J., \& Hwang, C. L. (1992). Fuzzy multiple attribute decision making: Methods and applications. Berlin: Springer-Verlag.

Cheng, C. H., Chen, C. T., \& Huang, S. F. (2012). Combining fuzzy integral with order weight average (OWA) method for evaluating financial performance in the semiconductor industry. African Journal of Business Management, 6(21), 6358-6368.

Csutora, R., \& Buckley, J. J. (2001). Fuzzy hierarchical analysis: the Lambda-Max method. Fuzzy sets and Systems, 120(2), 181-195.

Davoudi, M. R., \& Sheikhvand, K. (2012). An approach towards enterprise architecture analysis using AHP and fuzzy AHP. International Journal of Machine Learning and Computing, 2(1), 46-51.

Demirel, T., Demirel, N. Ç., \& Kahraman, C. (2010). Multi-criteria warehouse location selection using Choquet integral. Expert Systems with Applications, 37(5), 3943-3952.

Deng, H. (1999). Multicriteria analysis with fuzzy pair-wise comparison. International Journal of Approximate Reasoning, 21, 215-231.

Enea, M., \& Piazza, T. (2004). Project selection by constrained fuzzy AHP. Fuzzy Optimization and Decision Making (Vol. 3). New York: Kluwer Academic Publishers, 39-62.

Ghosh, D.N. (2011). Analytic Hierarchy Process \& TOPSIS Method to Evaluate Faculty Performance in Engineering Education. Dipendra Nath Ghosh et al UNIASCIT, 1(2), 63-70.

Güngör, Z., Serhadlıŏlu, G., \& Kesen, S. E. (2009). A Fuzzy AHP approach to staff selection problem. Applied Soft Computing ,9, 641-646.

Hota H.S., Sirigiri Pavani, P.V.S.S. Gangadhar (2013). Evaluating Teachers Ranking Using Fuzzy AHP Technique. International Journal of Soft Computing and Engineering (IJSCE), 2(6), 22312307.

Hwang, C. L., \& Yoon, K. (1981). Multiple attributes decision making methods and applications. Berlin: Springer.

Jessop, A. (2004). Minimally biased weight determination in staff. Journal of Operation Research, 153, 433-444.

Kahraman, C., Cebeci, U., \& Ruan, D. (2004). Multi-attribute comparison of catering service companies using fuzzy AHP: the case of Turkey. International Journal of Production Economics, 87(2), 171-184.

Kahraman, C., Cebeci, U., \& Ulukan, Z. (2003). Multi-criteria supplier selection using fuzzy AHP. Logistics Information Management, 16(6), 382-394.

Kahraman, C., Ruan, D., \& Doğan, I. (2003). Fuzzy group decision-making for facility location selection. Information Sciences, 157, 135-153.

Karsak, E. E. (2001).Staff selecting using a fuzzy MCDM approach based on ideal and anti-ideal solutions. Multiple Criteria Decision Making in the New Millennium, Springer.

Karmaker, C. L., \& Saha, M. (2015). Optimization of warehouse location through fuzzy multi-criteria 
decision making methods. Decision Science Letters, 4, 315-334 .

Kaufmann, A., \& Gupta, M. M. (1991). Introduction to fuzzy arithmetic: theory and applications. Arden Shakespeare.

Kelemenis \& D. Askounis (2010). A new TOPSIS-based multi-criteria approach to personnel selection. Expert Systems with Applications, 37, 4999-5008.

Kousalya, P., Ravindranath, V., \& Vizayakumar, K. (2006). Student Absenteeism in Engineering Colleges: Evaluation of Alternatives Using AHP. Journal of Applied Mathematics and Decision Sciences, 1-26.

Kumar, D. S., Radhika, S., \& Suman, K. N. S. (2013). MADM Methods for Finding The Right Personnel in Academic Institutions. International Journal of $u$ - and $e$-Service, Science and Technology, 6(5), 133-144.

Liang, G. S. (1999). Fuzzy MCDM based on ideal and anti-ideal concepts. European Journal of Operational Research, 112(3), 682-691.

Liang, S., \& Wang, M. J. J. (1994).Personnel selection using fuzzy MCDM algorithm. European Journal of Operational Research, 78, 22-33.

Lootsma, F. A. (1999). Multi-criteria decision analysis via ratio and difference judgment. Kluwer Academic Publishers.

Mahapatra, S. S., \& Khan, M. S. (2007). A Neural Network Approach for Assessing Quality in Technical Education: An Empirical Study. International Journal of Productivity and Quality Management, 2(3), 287-306.

Mikhailov, L. (2002). Fuzzy analytical approach to partnership selection in formation of virtual enterprises. Omega, 30, 393-401.

Mikhailov, L., \& Tsvetinov, P. (2004). Evaluation of services using a fuzzy analytic hierarchy process. Applied Soft Computing, 5(1), 23-33.

Miller, G. M., \& Feinzing, S. L. (1993)Fuzzy sets and staff selection: discussion and application. Journal of Occupational and Organizational Psychology, 66, 163-169.

Neogi, A., Mondal, A. C., \& Mandal, S. K. (2011). A Cascaded Fuzzy Inference System for University Non-Teaching Staff Performance Appraisal. Journal of Information Processing Systems, 7(4).

Özdağoğlu, A., \& Özdağoğlu, G. (2007). Comparison of AHP and fuzzy AHP for the multi-criteria decision making processes with linguistic evaluations. Istanbul Commerce University Journal of Science, 6(11), 65-85.

Radhika, S., Kumar, D. S., \& Swapna, D. (2013). VIKOR Method for Multi Criteria Decision Making in academic staff Selection. Journal of Production Research and Management, 3(2), 30-35.

Saaty, T. L. (1980). The analytic hierarchy process. New York: McGraw-Hill.

Van Laarhoven P.J. M., \& Pedrcyz, W. (1983). A fuzzy extension of Saaty’s priority theory. Fuzzy Sets and Systems, 11, 229-241.

Wang, T. C., \& Chang, T. H. (2007). Application of TOPSIS in evaluating initial training aircraft under a fuzzy environment. Expert Systems with Applications, 33, 870-880.

Wang, T. C., \& Chen, Y. H. (2007). Applying consistent fuzzy preference relations to partnership selection. Omega, 35(4), 384-388.

Wang, Y. J., \& Lee, H. S. (2007). Generalizing TOPSIS for fuzzy multiple-criteria group decisionmaking. Computers and Mathematics with Applications, 53, 1762-1772.

Wang, Y. M., \& Elhag, T. M. S. (2006). Fuzzy TOPSIS method based on alpha level sets with an application to bridge risk assessment. Expert Systems with Applications, 31, 309-319.

Wang, Y. M., Yang, J. B., \& Xu, D. L. (2005). A two-stage logarithmic goal programming method for generating weights from interval comparison matrices. Fuzzy sets and systems, 152(3), 475-498.

Xu, R. (2000). Fuzzy least-squares priority method in the analytic hierarchy process. Fuzzy Sets and Systems, 112(3), 395-404.

Yoon, K. P., \& Hwang, C. L. (1995). Multiple attribute decision making. Thousand Oaks, CA: Sage Publication.

Zadeh LA (1965). Fuzzy sets. Information Control, 8(3), 338-353. 